\title{
Structural Growth, Rumen Development, and Metabolic and Immune Responses of Holstein Male Calves Fed Milk Through Step-Down and Conventional Methods
}

\author{
M. A. Khan, ${ }^{\star 1}$ H. J. Lee, ${ }^{\star 2}$ W. S. Lee, ${ }^{*}$ H. S. Kim, ${ }^{\star}$ K. S. Ki, ${ }^{\star}$ T. Y. Hur, ${ }^{\star}$ G. H. Suh, ${ }^{\star}$ \\ S. J. Kang, ${ }^{\star}$ and Y. J. Choit \\ *Dairy Cattle Research Division, National Livestock Research Institute, Cheonan, 330-880, Republic of Korea \\ †School of Agricultural Biotechnology, Seoul National University, Seoul, 151-742, Republic of Korea
}

\section{ABSTRACT}

Structural growth, feed consumption, rumen development, metabolic response, and immune response were studied in Holstein calves fed milk through either a conventional method or a step-down (STEP) method. In the conventional method, calves $(n=20)$ were fed colostrum and then milk at a rate of $10 \%$ of their BW for the entire period of $44 \mathrm{~d}$. In the STEP method, calves $(\mathrm{n}=20)$ were given colostrum and then milk at a rate of $20 \%$ of their BW for $23 \mathrm{~d}$, which was reduced (between d 24 to 28) to $10 \%$ of their BW for the remaining $16 \mathrm{~d}$. The calves on both methods were weaned gradually by diluting milk with water between d 45 and 49. After weaning, feed consumption, structural growth, and body weight gain were monitored until calves were 63 $\mathrm{d}$ of age. At d 63, twelve calves (6/treatment) were euthanized and rumen papillae length, papillae width, rumen wall thickness, and emptied forestomach weight were recorded. At wk 4, 7, and 9, ruminal contents were collected to enumerate rumen metabolites. The STEPfed calves consumed a greater amount of milk than conventionally fed calves during the pre-STEP ( 1 to 28), post-STEP (d 29 to 49), and preweaning (d 1 to 49) periods. Consumption of starter and hay was greater during the pre-STEP period and lesser during the postSTEP and postweaning (d 50 to 63) periods in calves on the conventional method than on the STEP method. Body weight gain and structural growth measurements of calves were greater on the STEP method than on the conventional method. A hypophagic condition caused by greater milk consumption depressed solid feed intake of STEP-fed calves during the pre-STEP period, and a hyperphagic response caused by a reduced nutrient supply from milk triggered their consumption of solid

Received February 10, 2007.

Accepted March 29, 2007.

${ }^{1}$ M. A. Khan designed and conducted this study as a part of postdoctoral research.

${ }^{2}$ Corresponding author: dadim922@rda.go.kr feed during the post-STEP and postweaning periods. Ruminal $\mathrm{pH}$ and concentrations of ammonia, total volatile fatty acids, acetate, propionate, butyrate, and plasma $\beta$-hydroxybutyrate were higher in calves on the STEP method and at weaning and postweaning (d 63) were lower in calves on the conventional method. Emptied weight of the forestomach, rumen wall thickness, papillae length, papillae width, and papillae concentration were higher in calves on the STEP method than in those on the conventional method. Blood glucose was lower, and blood urea nitrogen and $\beta$-hydroxybutyrate at weaning and postweaning were higher in STEP-fed calves. Serum IgG, IgA, and triglycerides for 1, 2, and 3 wk of age were higher in calves on the STEP method than in those on the conventional method. In conclusion, greater feed consumption, BW gain, and structural growth, and a more metabolically and physically developed rumen were observed in calves on the STEP method than in those on the conventional method.

Key words: weaning, rumen development, hormone, immunity

\section{INTRODUCTION}

To have good dairy replacement stock, an efficient calf-feeding system is crucial because it determines the future income and sustainability of a dairy enterprise. The amount and method of milk feeding to neonatal calves are known to have enormous effects on their performance, behavior, health, and welfare traits. Restricted milk feeding to calves generally depressed their growth (Jasper and Weary, 2002), health, and behavior (Huzzey et al., 2005) because of a poor nutrient supply (Khan et al., 2007), and ad libitum milk feeding to calves is known to delay the initiation of ruminal fermentation and development (Baldwin et al., 2004) because of depressed intake of solid feed (Hammon et al., 2002; Jensen, 2006; Quigley et al., 2006). Improvements to the nutritional regimen of the calf can decrease mortality and disease susceptibility and increase the rate of BW gain (Baldwin et al., 2004). In a recent study (Khan 
et al., 2007), we compared the pre- and postweaning performance of Holstein female calves fed milk with a conventional ( $10 \%$ of the calves' BW for $45 \mathrm{~d}$ ) or stepdown method (STEP, calves fed milk at $20 \%$ of their BW until $25 \mathrm{~d}$ of age, with milk gradually reduced to $10 \%$ of their BW for the remaining preweaning period). Significantly greater milk consumption, dry feed intake, BW gain, and feed efficiency were observed in calves on the STEP method compared with conventionally fed calves.

The process of transitioning calves from their neonatal reliance on nutrients supplied from milk to nutrients supplied from grain is of substantial economic importance to the producer (Baldwin et al., 2004). This transition results in tremendous metabolic ramifications for calf growth rate because tissues must convert from reliance on glucose supplied from milk to metabolism of short-chain fatty acids as primary energy substrates. In the preweaned dairy calf, solid feed intake, especially of a high-carbohydrate diet, stimulates rumen microbial proliferation and VFA production, subsequently initiating rumen development (Flatt et al., 1958; Harrison et al., 1960; Suárez et al., 2006). The difference in dry feed consumption of preweaned calves and the amount and method of milk feeding may affect metabolic, endocrine, and immunological traits; further, it may influence the initiation of rumen fermentation and rumen development. The objectives of this study were to compare the effects of STEP milk feeding with conventional milk feeding on structural growth, ruminal development, and metabolic and immune responses in Holstein male calves.

\section{MATERIALS AND METHODS}

\section{Calves, Management, Feeding, and Treatments}

All experimental procedures were reviewed and approved by the ethics committee on the use of animals in research, National Livestock Research Institute, South Korea. Male Holstein calves $(\mathrm{n}=40)$ born between December 2005 and February 2006 were separated from their mothers within $2 \mathrm{~h}$ of birth, weighed, and moved into individual pens $(1.5 \times 2.5 \mathrm{~m}$, bedded with wood shavings), where they were fed colostrum at $10 \%$ of their BW for the first $3 \mathrm{~d}$. The individual pens were interspersed evenly throughout the calf barn. Pens had solid iron rod sides, with openings in the front and rear to allow the calves free access to calf starter and chopped mixed grass hay (MGS) from feeding buckets. The chemical composition of the calf starter and hay is given in Table 1. Calves were provided free access to water from a bowl drinker in each pen.

All calves were fed whole milk stored in a milk tank at 4 to $6^{\circ} \mathrm{C}$ after milking. Prior to feeding the milk, the
Table 1. Chemical composition of calf starter (CS) and mixed grass hay (MGS) on a DM basis

\begin{tabular}{|c|c|c|}
\hline Composition, \% & $\mathrm{CS}(\mathrm{n}=10)$ & $\operatorname{MGS}^{1}(\mathrm{n}=10)$ \\
\hline DM & $88.80 \pm 0.50$ & $90.80 \pm 0.74$ \\
\hline $\mathrm{CP}$ & $21.95 \pm 0.20$ & $14.02 \pm 0.50$ \\
\hline Total digestible nutrients ${ }^{2}$ & $73.4 \pm 1.54$ & $56.2 \pm 1.74$ \\
\hline $\mathrm{NDF}$ & $11.4 \pm 0.70$ & $63.9 \pm 3.01$ \\
\hline $\mathrm{ADF}$ & $5.44 \pm 0.60$ & $34.7 \pm 2.5$ \\
\hline Ash & $3.60 \pm 0.22$ & $6.90 \pm 0.15$ \\
\hline $\mathrm{Ca}$ & $0.18 \pm 0.02$ & $0.70 \pm 0.1$ \\
\hline Phosphorus & $0.54 \pm 0.05$ & $0.31 \pm 0.08$ \\
\hline
\end{tabular}

${ }^{1}$ MGS contained $43 \%$ orchard grass, $43 \%$ tall fescue, and $14 \%$ white clover on a DM basis.

${ }^{2}$ Calculated using the equation of the NRC (2001).

temperature was raised in steel buckets using a water bath at 36 to $37^{\circ} \mathrm{C}$. Colostrum and milk samples were analyzed with a LactoScope (MK2, Delta Instruments, the Netherlands). The LactoScope was standardized for colostrum prior to analysis. The chemical composition of colostrum and milk is presented in Table 2.

All calves were fed milk using mobile plastic bottles (2-L capacity) fitted with soft rubber nipples. A steel bottle stand was attached to an iron rod at the front side of individual pens at $70 \mathrm{~cm}$ above the floor. At each feeding, a bottle containing milk was fitted into the stand and removed after feeding. After each feeding, the bottles were washed using an iodine detergent, dried, and stored in an inverted position.

For calves $(n=20)$ fed using the conventional method, milk was provided at the rate of $10 \%$ of their BW until d 44 of age. Calves in the conventional method were fed milk twice daily ( 0800 and $1700 \mathrm{~h}$ ) in equally divided amounts. Between d 45 and 49 of age, the calves were weaned gradually by diluting milk with water. The amount of water was increased by $10 \%$ of the total volume at each feeding so that on the morning of $d 50$, all the calves received $100 \%$ water. The calves continued to receive water from the milk bottles until d 52, in addition to the water that was always available from the bowl drinker. This weaning method was used to reduce the variation in weight gain and solid feed intake and thus provide a more sensitive test of the feeding treatment than would be possible with abrupt weaning.

For calves $(n=20)$ fed using the STEP method, milk was provided at the rate of $20 \%$ of their BW until d 23 of age, and then between $d 24$ to 28 this rate was gradually reduced by diluting the milk with water $(10 \%$ of the volume on each feeding) until a milk feeding rate of $10 \%$ of their BW was achieved. Calves were fed at this rate for the remaining $16 \mathrm{~d}$ of the weaning period. The STEP-fed calves were weaned between d 44 and 49 as described previously for conventionally fed calves. During the first phase of STEP milk feeding (pre-STEP, from birth to d 28 of the calf age), the calves were fed 
Table 2. Chemical composition (mean \pm SE) of colostrum and milk

\begin{tabular}{lcccr}
\hline & \multicolumn{3}{c}{ Colostrum $^{1}$} \\
\cline { 2 - 4 } Composition & Day 1 & Day 2 & Day 3 & Milk $^{2}$ \\
\hline Fat, \% & $5.9 \pm 0.20$ & $4.5 \pm 0.32$ & $3.98 \pm 0.15$ & $3.78 \pm 0.14$ \\
Protein, \% & $17.6 \pm 0.4$ & $8.90 \pm 0.15$ & $5.52 \pm 0.1$ & $3.48 \pm 0.08$ \\
Lactose, \% & $3.19 \pm 0.02$ & $3.65 \pm 0.03$ & $4.38 \pm 0.03$ & $4.76 \pm 0.03$ \\
TS, \% & $26.62 \pm 0.5$ & $17.0 \pm 0.2$ & $13.93 \pm 0.1$ & $12.10 \pm 0.2$ \\
FFA, mEq/dL & $1.5 \pm 0.06$ & $0.90 \pm 0.05$ & $0.80 \pm 0.05$ & $0.67 \pm 0.05$ \\
Citrate, mg/L & $0.05 \pm 0.01$ & $0.18 \pm 0.02$ & $0.14 \pm 0.01$ & $0.17 \pm 0.01$ \\
MUN, mg/dL & $\mathrm{ND}^{3}$ & $\mathrm{ND}$ & $\mathrm{ND}$ & $25.15 \pm 3.45$ \\
$\mathrm{Ca}, \mathrm{mg} / \mathrm{dL}$ & $190 \pm 0.05$ & $145 \pm 0.07$ & $129 \pm 0.08$ & $117 \pm 0.05$ \\
$\mathrm{P}, \mathrm{mg} / \mathrm{dL}$ & $165 \pm 0.08$ & $135 \pm 0.05$ & $102 \pm 0.06$ & $74 \pm 0.2$ \\
\hline
\end{tabular}

${ }^{1}$ Each day, a.m. and p.m. colostrum samples were composited for analysis $(n=40)$.

${ }^{2}$ Milk storage tank samples $(n=16)$.

${ }^{3} \mathrm{ND}=$ not determined.

milk in evenly spaced feeding frequencies (minimum 2 $\mathrm{h}$ between successive feedings) in such a way that each calf did not receive more than $2 \mathrm{~L}$ of milk at each feeding. During the second phase of STEP milk feeding (post-STEP, from d 29 to 49 of calf age), the calves were fed milk twice daily ( 0800 and $1700 \mathrm{~h}$ ) in equally divided amounts. After weaning, feed consumption, structural growth, and BW gain were monitored until calves were $63 \mathrm{~d}$ of age.

\section{Sampling and Analysis}

The BW of calves and their intake of starter and MGS were recorded twice weekly. Polyethene sheets were attached around each feeding bucket to account for wastage of calf starter and hay. Calf starter, MGS, and refusals were sampled and analyzed for DM by the method of AOAC (AOAC, 1990). Body length (BL), heart girth (HG), body barrel (BB), withers height (WH), and hip height (HH) measurements of the calves were recorded at birth, at STEP (d 28) and weaning (d 49 ), and at postweaning (d 63).

Dry matter intake of calf starter and MGS and of dry feed by calves in the STEP and conventional groups were calculated for each of the 3 phases of the experiment, pre-STEP, post-STEP, and postweaning (d 50 to 63). Average weight gain, total DMI (milk solids, starter and hay), and feed efficiency (feed efficiency $=\mathrm{kg}$ of BW gain $/ \mathrm{kg}$ of total DMI) were calculated for 4 different periods, pre-STEP, post-STEP, preweaning (d 1 to 49), and postweaning.

Jugular blood samples were collected $30 \mathrm{~min}$ before the morning feeding $(0730 \mathrm{~h})$ weekly throughout the experiment in evacuated tubes $(10 \mathrm{~mL})$ without any anticoagulant. These samples were centrifuged at 1,000 $\times g$ for 20 min, and serum was partitioned into aliquots and stored at $-20^{\circ} \mathrm{C}$ until analyzed for glucose, total protein, BUN, triglycerides, and NEFA by a serum ana- lyzer (Arco PC, Biotecnica Instruments, Rome, Italy). Immunoglobulin $\mathrm{G}$ and IgA concentrations were determined in weekly serum samples by RIA (Bethyl Laboratories, Montgomery, AL) in comparison with a standard curve, according to the manufacturer's instructions. Jugular blood samples were also collected weekly and additionally at $\mathrm{d} 23,25,27$, and 30 in evacuated tubes $(5 \mathrm{~mL})$ containing dipotassium-EDTA ( $1.8 \mathrm{~g} / \mathrm{L}$ of blood), and plasma was harvested for determination of insulin and glucagon concentrations by the RIA method as described by Hammon and Blum (1998). Plasma BHBA was determined in samples taken at wk 4 (STEP), 7 (weaning), and 9 (postweaning) using the Stanbio BHBA LiquiColor kit (procedure no. 2440, Stanbio Laboratory, Boerne, TX).

At wk 4, 7, and 9, ruminal contents were collected at approximately $3 \mathrm{~h}$ postfeeding with a stomach tube and a large syringe. Sample pH was determined immediately with a $\mathrm{pH}$ meter (HM-21P, TOA Corporation, Tokyo, Japan). Ruminal contents were squeezed through 4 layers of cheesecloth, and rumen fluid (15 $\mathrm{mL}$ ) samples were taken in tubes, placed on ice, and transported to the laboratory, where they were acidified with $3 \mathrm{~mL}$ of $25 \%$ metaphosphoric acid and $3 \mathrm{~mL}$ of $0.6 \%$ 2-ethyl butyric acid (internal standard) and stored $\left(-20^{\circ} \mathrm{C}\right)$ until analyzed for VFA and ammonia. Samples were later centrifuged twice at $4,500 \times g$ for $30 \mathrm{~min}$ at $4^{\circ} \mathrm{C}$ to obtain a clear supernatant. The supernatant was analyzed for rumen ammonia with a phenolhypochlorite assay (Broderick and Kang, 1980) and for molar concentration of VFA by GLC.

At $d$ 63, twelve calves (6/treatment) were randomly selected, euthanized by captive bolt stunning, and exsanguinated. Digestive tracts were harvested, emptied, and rinsed with cold water, and rumen tissue samples were collected for analysis of papillae length (PL), papillae width (PW), and rumen wall thickness according to Lesmeister et al. (2004). Emptied weights of the rumen, 


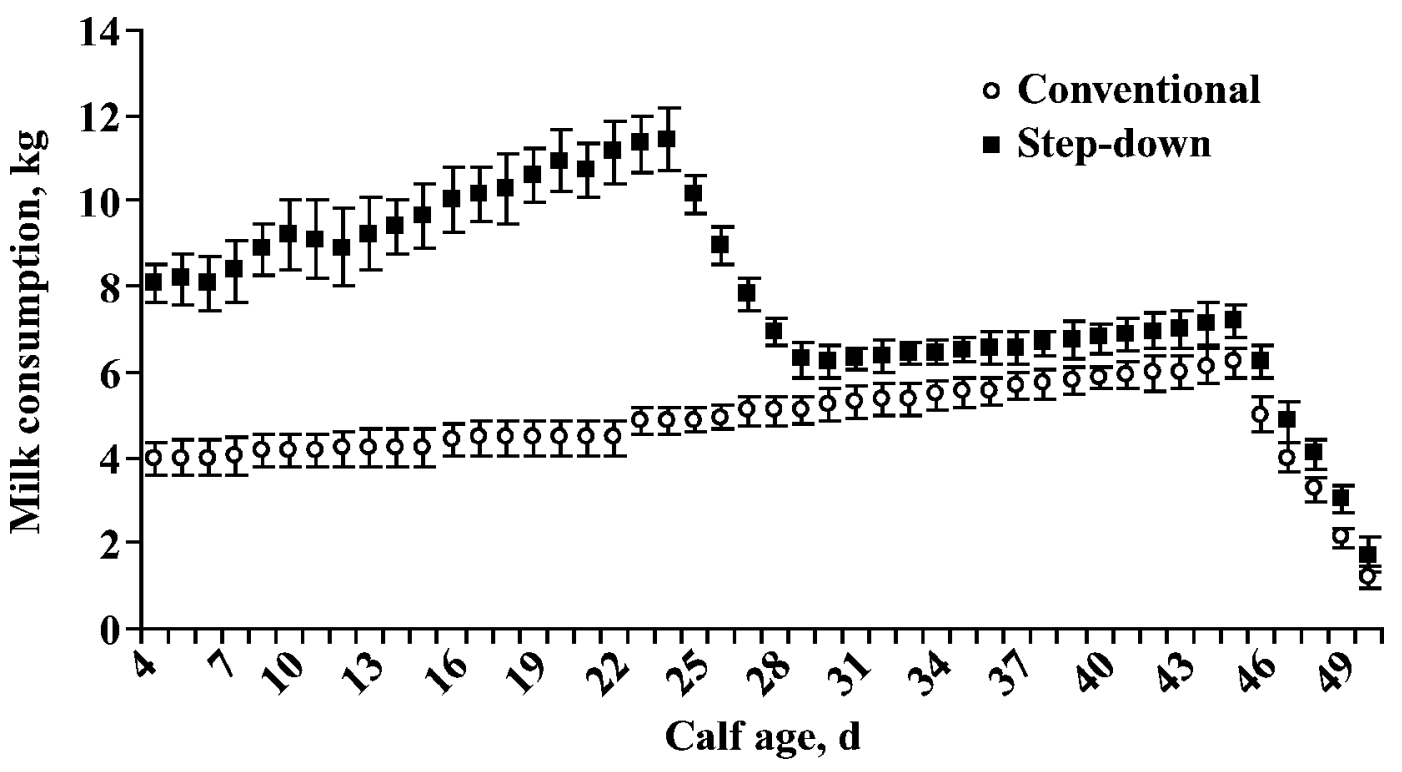

Figure 1. Mean $( \pm$ SE) daily intake of milk, measured in kilograms. Values are shown separately for Holstein male calves fed milk either conventionally $(\mathrm{n}=20)$ or through a step-down (STEP; $\mathrm{n}=20$ ) procedure. In the conventional method, calves were fed colostrum for $3 \mathrm{~d}$ and then milk at the rate of $10 \%$ of their BW until d 44 of age. In the STEP method, calves were given colostrum for $3 \mathrm{~d}$ and then milk until $23 \mathrm{~d}$ of age at $20 \%$ of their BW, which was gradually reduced (between d 24 and 28) to $10 \%$ of their BW for the remaining $16 \mathrm{~d}$ of the weaning period. Calves in both the conventional and STEP groups were weaned gradually by diluting milk with water between $\mathrm{d} 45$ and 49 of age.

reticulum, omasum, and abomasa were measured and papillae concentration was recorded.

The health of calves was monitored by using the procedure described by Heinrichs et al. (2003). Scoring was as follows: for scour scoring, $1=$ normal, $2=$ soft to loose, $3=$ loose to watery, $4=$ watery, mucous, slightly bloody, 5 = watery, mucous, and bloody; for respiratory scoring, 1 = normal, 2 = slight cough, 3 = moderate cough, $4=$ moderate to severe cough, $5=$ severe and chronic cough; and for general appearance scoring, $1=$ normal and alert, 2 = ears drooped, $3=$ head and ears drooped, dull eyes, slightly lethargic, $4=$ head and ears drooped, dull eyes, lethargic, $5=$ severely lethargic. A scour day was considered if the scour score was $>3$. Scours were also treated with electrolyte therapy (3 g/ L in drinking water; Eltradd, Byer Animal Health Co., Suwan, South Korea).

\section{Statistical Analysis}

Overall differences in feed consumption were evaluated by means of Wilcoxon's 2-sample test (SAS Institute, 1994) because data were not normally distributed. Treatment differences for overall BW gain, structural growth, feed efficiency, ruminal parameters, and health scouring data were evaluated by Student's $t$-test. For time and treatment differences, concentrations of blood metabolites, Ig, and hormones were evaluated using the RANDOM and REPEATED methods of SAS PROC MIXED (SAS Institute, 1994). Treatment (i.e., conventional and STEP milk feeding) and time were used as fixed effects and the individual calves were used as random effects. For analyses of differences in the time pattern between groups, the interaction (treatment $x$ time) was included in the model. Treatment differences at specific time points were localized by Bonferroni's $t$ test $(P<0.05)$.

\section{RESULTS}

Mean milk consumption was higher in STEP-fed calves than in those fed conventionally during the preSTEP and post-STEP periods (Figure 1). The STEP-fed calves consumed 109.5, 17.6, and 51.6\% more milk than conventionally fed calves during the pre-STEP, postSTEP, and preweaning periods, respectively (Table 3).

Starter and hay consumption was increased with age in calves fed through the conventional and STEP methods; however, a rapid increase in intake of both starter and hay was observed after d 28 in calves fed milk through the STEP procedure (Figure 2). A pronounced surge in solid feed consumption was noticed in both groups during weaning and within a few days of postweaning. Mean starter and hay consumption was lower $(P<0.012$ and $P<0.034$, respectively) during the preSTEP period and was higher during the post-STEP $(P$ 
Table 3. Average daily milk, starter, and mixed grass hay intake by Holstein male calves fed milk through either a conventional $(\mathrm{n}=20)$ or step-down (STEP, $\mathrm{n}=20$ ) procedure $^{1}$

\begin{tabular}{lrrr}
\hline Parameter & Conventional & STEP & SEM \\
\hline Milk intake, kg & & & \\
Pre-STEP (d 1 to 28) & $4.41^{\mathrm{b}}$ & $9.24^{\mathrm{a}}$ & 0.54 \\
Post-STEP (d 29 to 49) & $5.17^{\mathrm{b}}$ & $6.08^{\mathrm{a}}$ & 0.36 \\
Preweaning (d 1 to 49) & $4.74^{\mathrm{b}}$ & $7.84^{\mathrm{a}}$ & 0.47 \\
Starter intake, g/d & & & \\
Pre-STEP & $171.56^{\mathrm{a}}$ & $148.00^{\mathrm{b}}$ & 10.35 \\
Post-STEP & $704.58^{\mathrm{b}}$ & $996.42^{\mathrm{a}}$ & 20.36 \\
Preweaning & $400.00^{\mathrm{b}}$ & $511.61^{\mathrm{a}}$ & 18.23 \\
Postweaning (d 50 to 63) & $1,534.38^{\mathrm{b}}$ & $2,086.88^{\mathrm{a}}$ & 56.11 \\
Mixed grass hay, g & & & \\
Pre-STEP & $45.94^{\mathrm{b}}$ & $32.50^{\mathrm{a}}$ & 5.61 \\
Post-STEP & $102.92^{\mathrm{b}}$ & $135.00^{\mathrm{a}}$ & 13.24 \\
Preweaning & $70.36^{\mathrm{b}}$ & $86.43^{\mathrm{a}}$ & 12.36 \\
Postweaning & $260.63^{\mathrm{b}}$ & $357.50^{\mathrm{a}}$ & 20.96 \\
\hline
\end{tabular}

${ }^{\mathrm{a}, \mathrm{b}}$ Within traits, means with different superscript letters are different $(P<0.05)$.

${ }^{1}$ In the conventional method, the calves were fed colostrum for 3 $\mathrm{d}$ and then milk at $10 \%$ of BW until $44 \mathrm{~d}$ of age. In the STEP method, the calves were given colostrum for $3 \mathrm{~d}$ and then milk until $23 \mathrm{~d}$ of age at $20 \%$ of BW, which was gradually reduced (between d 24 and 28 ) to $10 \%$ of BW for the remaining $16 \mathrm{~d}$ of the weaning period. Calves in both the conventional and STEP groups were weaned gradually by diluting milk with water between 45 and $49 \mathrm{~d}$ of age.

$<0.014$ and $P<0.021$, respectively), preweaning $(P<$ 0.012 and $P<0.032$, respectively), and postweaning ( $P$ $<0.011$ and $P<0.004$, respectively) periods in calves on the STEP method compared with those on the conventional method.

Mean $( \pm$ SE) BW of STEP-fed and conventionally fed calves are shown in Figure 2. Mean birth BW, BL, HG, $\mathrm{BB}, \mathrm{WH}$, and $\mathrm{HH}$ in conventionally fed and STEP-fed calves were the same (Table 4). Body weight, BL, HG, $\mathrm{BB}, \mathrm{WH}$, and $\mathrm{HH}$ were higher at the STEP $(P<0.002$, $P<0.002, P<0.002, P<0.001, P<0.002$, and $P<0.001$, respectively), weaning $(P<0.003, P<0.002, P<0.004$, $P<0.002, P<0.003$, and $P<0.002$, respectively), and postweaning $(P<0.002, P<0.003, P<0.004, P<0.003$, $P<0.002$, and $P<0.002$, respectively) periods in calves on the STEP method compared with those on the conventional method.

Total DMI from solid feed and milk were 74.1, 24.3, 47.5 , and $37.3 \%$ higher during the pre-STEP, postSTEP, preweaning, and postweaning periods, respectively, in STEP-fed calves compared with those fed conventionally (Table 5). The STEP-fed calves gained 89.6, $17.36,50.1$, and $30.3 \%$ more BW than conventionally fed calves during the pre-STEP, post-STEP, preweaning, and postweaning periods, respectively. Feed efficiency was higher $(P<0.002)$ during the pre-STEP period and lower $(P<0.021)$ during the post-STEP period in calves on the STEP method than in those on the conventional method. Feed efficiency was similar in STEP-fed and conventionally fed calves during the pre- weaning and postweaning periods (Table 5). Days scoured, rectal temperature, respiratory score, and general appearance score in this study were similar in STEP-fed and conventionally fed calves. No sign of any disease other than diarrhea was noticed during the experiment in calves fed milk through either the STEP or the conventional method.

Ruminal pH was lower $(P<0.031)$ and ruminal ammonia concentration was higher $(P<0.021)$ at STEP in conventionally fed calves than in those fed through the STEP method (Table 6). At weaning and postweaning, ruminal $\mathrm{pH}$ was higher $(P<0.012$ and $P<0.015$, respectively) and ruminal ammonia concentration was lower $(P<0.011$ and $P<0.07$, respectively) in calves on the conventional method compared with those on the STEP method.

Ruminal total VFA, acetate, propionate, and butyrate concentrations at STEP were higher $(P<0.001, P<$ $0.022, P<0.031$, and $P<0.034$, respectively) in conventionally fed calves than in STEP-fed calves (Table 7). Concentrations of total VFA, acetate, propionate, and butyrate were lower in conventionally fed calves than in STEP-fed calves at weaning $(P<0.003, P<0.001, P$ $<0.002$, and $P<0.026$, respectively) and postweaning $(P<0.002, P<0.002, P<0.019$, and $P<0.021$, respectively).

Plasma BHBA concentration at STEP was similar $(P$ $<0.121$ ) in conventionally fed and STEP-fed calves. However, at weaning and postweaning, plasma BHBA was higher $(P<0.0018$ and $P<0.014$, respectively) in calves on the STEP method than in those on the conventional method (Table 7).

Emptied weights of the rumen, reticulum, omasum, and abomasa were higher $(P<0.031, P<0.034, P<$ 0.001 , and $P<0.002$, respectively) in calves on the STEP method than in those on the conventional method (Table 8). Rumen wall thickness, PL, PW, and papillae concentration were also greater $(P<0.014, P<0.002$, $P<0.016$, and $P<0.001$, respectively) in STEP-fed calves than in those fed conventionally (Table 8).

Blood glucose was decreased $(P<0.01)$ with increasing age in calves fed through the STEP and conventional methods (Table 9). Blood glucose concentration was lower $(P<0.001)$ in STEP-fed calves than in those fed conventionally at $\mathrm{d} 35,42,49,56$, and 63 of age. Total blood protein was not affected by the treatment or age of the calves. Blood urea nitrogen was increased $(P<0.01)$ with calf age; however, BUN concentration was greater $(P<0.01)$ in calves fed milk through the STEP procedure than in those fed conventionally at $d$ $42,49,56$, and $63 \mathrm{~d}$ of age. Blood triglycerides were affected $(P<0.02)$ by calf age and their concentration was greater $(P<0.01)$ at d 7,14,21, and 28 in calves fed through the STEP procedure than in those fed con- 

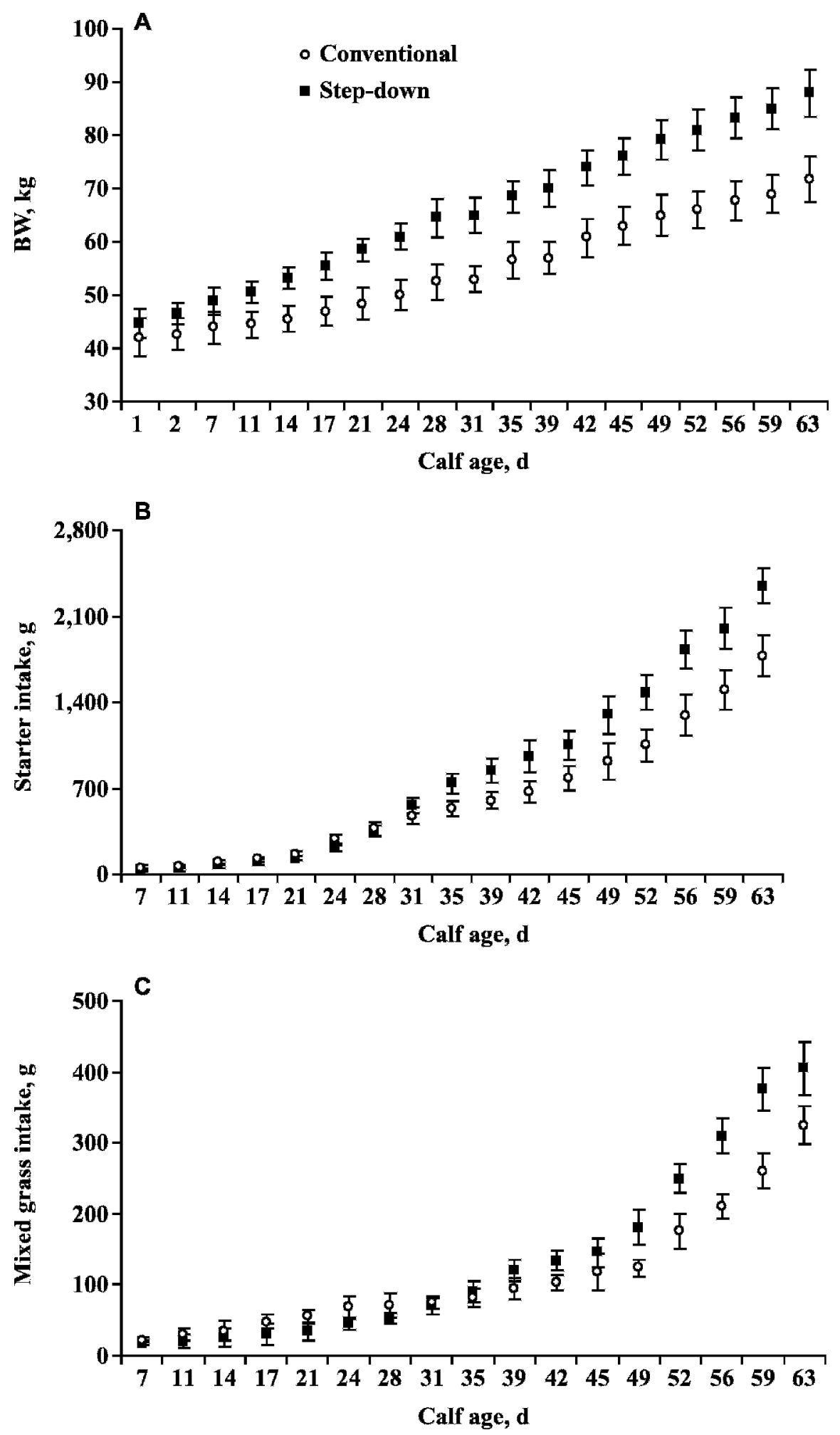

Figure 2. Mean $( \pm \mathrm{SE})$ weekly BW (A), starter intake (B), and mixed grass hay intake (C). Values are shown separately for Holstein male calves fed milk either conventionally $(\mathrm{n}=20)$ or through a step-down (STEP; $\mathrm{n}=20$ ) procedure. In the conventional method, calves were fed colostrum for $3 \mathrm{~d}$ and then milk at the rate of $10 \%$ of their BW until d 44 of age. In the STEP method, calves were given colostrum for $3 \mathrm{~d}$ and then milk until $23 \mathrm{~d}$ of age at $20 \%$ of their BW, which was gradually reduced (between d 24 and 28 ) to $10 \%$ of their BW for the remaining $16 \mathrm{~d}$ of the weaning period. Calves in both the conventional and STEP groups were weaned gradually by diluting milk with water between $\mathrm{d} 45$ and 49 of age. 
Table 4. Average BW and body measurements of Holstein male calves fed milk through either a conventional $(n=20)$ or step-down (STEP, $\mathrm{n}=20$ ) procedure $^{1}$

\begin{tabular}{|c|c|c|c|}
\hline Parameter & Conventional & STEP & SEM \\
\hline \multicolumn{4}{|l|}{ BW, kg } \\
\hline At birth & 42.13 & 44.78 & 3.12 \\
\hline At STEP (d 28) & $52.50^{\mathrm{b}}$ & $64.44^{\mathrm{a}}$ & 2.14 \\
\hline At weaning (d 49) & $65.00^{\mathrm{b}}$ & $79.11^{\mathrm{a}}$ & 3.35 \\
\hline At postweaning (d 63) & $71.75^{\mathrm{b}}$ & $87.89^{\mathrm{a}}$ & 4.54 \\
\hline \multicolumn{4}{|l|}{ Body length, $\mathrm{cm}$} \\
\hline At birth & 61.56 & 62.8 & 3.23 \\
\hline At STEP & $69.50^{\mathrm{b}}$ & $75.45^{\mathrm{a}}$ & 2.31 \\
\hline At weaning & $77.48^{\mathrm{b}}$ & $84.11^{\mathrm{a}}$ & 2.36 \\
\hline At postweaning & $83.66^{\mathrm{b}}$ & $91.22^{\mathrm{a}}$ & 2.74 \\
\hline \multicolumn{4}{|l|}{ Heart girth, cm } \\
\hline At birth & 68.56 & 70.25 & 3.66 \\
\hline At STEP & $77.74^{\mathrm{b}}$ & $85.42^{\mathrm{a}}$ & 2.92 \\
\hline At weaning & $86.66^{\mathrm{b}}$ & $95.22^{\mathrm{a}}$ & 2.84 \\
\hline At postweaning & $92.71^{\mathrm{b}}$ & $105.33^{\mathrm{a}}$ & 3.13 \\
\hline \multicolumn{4}{|l|}{ Body barrel, cm } \\
\hline At birth & 68.56 & 70.11 & 3.33 \\
\hline At STEP & $82.83^{\mathrm{b}}$ & $90.11^{\mathrm{a}}$ & 2.77 \\
\hline At weaning & $93.01^{\mathrm{b}}$ & $102.31^{\mathrm{a}}$ & 2.84 \\
\hline At postweaning & $99.73^{\mathrm{b}}$ & $110.2^{\mathrm{a}}$ & 3.23 \\
\hline \multicolumn{4}{|l|}{ Hip height, $\mathrm{cm}$} \\
\hline At birth & $68.84^{\mathrm{b}}$ & 69.56 & 3.66 \\
\hline At STEP & $76.42^{\mathrm{b}}$ & $84.36^{\mathrm{a}}$ & 2.68 \\
\hline At weaning & $83.36^{\mathrm{b}}$ & $94.52^{\mathrm{a}}$ & 2.94 \\
\hline At postweaning & $89.66^{\mathrm{b}}$ & $104.2^{\mathrm{a}}$ & 2.69 \\
\hline \multicolumn{4}{|l|}{ Wither height, cm } \\
\hline At birth & 65.20 & 66.32 & 3.54 \\
\hline At STEP & $72.71^{\mathrm{b}}$ & $80.21^{\mathrm{a}}$ & 2.63 \\
\hline At weaning & $80.41^{\mathrm{b}}$ & $89.23^{\mathrm{a}}$ & 2.19 \\
\hline At postweaning & $85.64^{\mathrm{b}}$ & $100.11^{\mathrm{a}}$ & 3.44 \\
\hline
\end{tabular}

${ }^{\mathrm{a}, \mathrm{b}}$ Within traits, means with different superscript letters are different $(P<0.05)$.

${ }^{1}$ In the conventional method, the calves were fed colostrum for 3 $\mathrm{d}$ and then milk at $10 \%$ of BW until $44 \mathrm{~d}$ of age. In the STEP method, the calves were given colostrum for $3 \mathrm{~d}$ and then milk until $23 \mathrm{~d}$ of age at $20 \%$ of BW, which was gradually reduced (between $\mathrm{d} 24$ and 28 ) to $10 \%$ of BW for the remaining $16 \mathrm{~d}$ of the weaning period. Calves in both the conventional and STEP groups were weaned gradually by diluting milk with water between 45 and $49 \mathrm{~d}$ of age.

ventionally. Blood NEFA concentration was affected by calf age $(P<0.01)$. The treatment $\times$ time interaction for NEFA in calves at $63 \mathrm{~d}$ was also significant $(P<$ $0.02)$. The concentration of blood NEFA was higher $(P$ $<0.001)$ at $\mathrm{d} 7,14$, and 21 and lower $(P<0.001)$ at $\mathrm{d}$ 49 and 56 in calves fed through the STEP procedure compared with those fed conventionally. Serum IgG concentration was affected $(P<0.01)$ by calf age, and IgG concentration was higher $(P<0.02)$ at $d 7,14$, and 21 in STEP-fed calves than in those fed conventionally. Serum IgA concentration was also affected $(P<0.03)$ by calf age, and was higher $(P<0.04)$ in calves fed through the STEP procedure than in those fed conventionally (Table 9). The treatment $\times$ time interaction for serum IgA in calves at $63 \mathrm{~d}$ was also significant $(P$ $<0.02$ ).

Plasma glucagon concentration was higher $(P<0.02)$ and plasma insulin concentration was lower $(P<0.01)$
Table 5. Average total DMI, BW gain, feed efficiency, rectal temperature, respiratory score, and general scores of Holstein male calves fed milk through either a conventional $(n=20)$ or step-down (STEP, $\mathrm{n}=20$ ) procedure $^{1}$

\begin{tabular}{lccc}
\hline Parameter $^{2}$ & Conventional & STEP & SEM \\
\hline Total DMI, kg & & & \\
Pre-STEP (d 1 to 28) & $21.84^{\mathrm{b}}$ & $38.03^{\mathrm{a}}$ & 2.44 \\
Post-STEP (d 29 to 49) & $25.11^{\mathrm{b}}$ & $31.21^{\mathrm{a}}$ & 2.17 \\
Preweaning (d 1 to 49) & $46.95^{\mathrm{b}}$ & $69.24^{\mathrm{a}}$ & 3.20 \\
Postweaning (d 50 to 63) & $21.35^{\mathrm{b}}$ & $29.32^{\mathrm{a}}$ & 1.26 \\
BW gain, kg & & & \\
Pre-STEP & $10.37^{\mathrm{b}}$ & $19.66^{\mathrm{a}}$ & 1.12 \\
Post-STEP & $12.5^{\mathrm{b}}$ & $14.67^{\mathrm{a}}$ & 1.02 \\
Preweaning & $22.87^{\mathrm{b}}$ & $34.33^{\mathrm{a}}$ & 2.31 \\
Postweaning & $6.75^{\mathrm{b}}$ & $8.78^{\mathrm{a}}$ & 0.54 \\
Feed efficiency & & & \\
Pre-STEP & $0.47^{\mathrm{b}}$ & $0.52^{\mathrm{a}}$ & 0.01 \\
Post-STEP & $0.50^{\mathrm{a}}$ & $0.47^{\mathrm{b}}$ & 0.02 \\
Preweaning & 0.49 & 0.50 & 0.02 \\
Postweaning & 0.32 & 0.30 & 0.01 \\
Days scoured & 7.15 & 7.34 & 1.20 \\
Respiratory score & 1.18 & 1.11 & 0.11 \\
Rectal temperature & 38.82 & 38.90 & 0.12 \\
General appearance & 1.21 & 1.15 & 0.10 \\
\hline
\end{tabular}

${ }^{a, b}$ Within traits, means with different superscript letters are different $(P<0.05)$

${ }^{1}$ In the conventional method, the calves were fed colostrum for 3 $\mathrm{d}$ and then milk at $10 \%$ of BW until $44 \mathrm{~d}$ of age. In the STEP method, the calves were given colostrum for $3 \mathrm{~d}$ and then milk until $23 \mathrm{~d}$ of age at $20 \%$ of BW, which was gradually reduced (between $d 24$ and 28 ) to $10 \%$ of BW for the remaining $16 \mathrm{~d}$ of the weaning period. Calves in both the conventional and STEP groups were weaned gradually by diluting milk with water between 45 and $49 \mathrm{~d}$ of age.

${ }^{2} \mathrm{DMI}=$ milk, starter, and hay DMI. Feed efficiency $=\mathrm{kg}$ of BW gain/kg of DMI. Scour scoring: $1=$ normal, $2=$ soft to loose, $3=$ loose to watery, 4 = watery, mucous, slightly bloody, 5 = watery, mucous, and bloody. Scour day considered if score $>3$. Respiratory scoring: $1=$ normal, $2=$ slight cough, $3=$ moderate cough, $4=$ moderate to severe cough, $5=$ severe and chronic cough. General appearance scoring: $1=$ normal and alert, 2 = ears drooped, $3=$ head and ears drooped, dull eyes, slightly lethargic, $4=$ head and ears drooped, dull eyes, lethargic, 5 = severely lethargic.

Table 6. Average ruminal $\mathrm{pH}$ and ammonia concentrations in Holstein male calves fed milk through either a conventional $(n=20)$ or step-down $\left(\mathrm{STEP}, \mathrm{n}=20\right.$ ) procedure $^{1}$

\begin{tabular}{lccc}
\hline Parameter & Conventional & STEP & SEM \\
\hline Ruminal pH & & & \\
At STEP (d 28) & $6.07^{\mathrm{b}}$ & $6.46^{\mathrm{a}}$ & 0.11 \\
At weaning (d 49) & $6.22^{\mathrm{a}}$ & $5.66^{\mathrm{b}}$ & 0.22 \\
At postweaning (d 63) & $6.042^{\mathrm{a}}$ & $5.72^{\mathrm{b}}$ & 0.12 \\
Ruminal ammonia, mmol/L & & & \\
At STEP & $6.21^{\mathrm{a}}$ & $5.92^{\mathrm{b}}$ & 0.34 \\
At weaning & $7.12^{\mathrm{b}}$ & $9.98^{\mathrm{a}}$ & 0.65 \\
At postweaning & $9.54^{\mathrm{b}}$ & $13.61^{\mathrm{a}}$ & 0.82 \\
\hline
\end{tabular}

a,b Within traits, means with different superscript letters are significantly different $(P<0.05)$.

${ }^{1}$ In the conventional method, the calves were fed colostrum for 3 $\mathrm{d}$ and then milk at $10 \%$ of BW until $44 \mathrm{~d}$ of age. In the STEP method, the calves were given colostrum for $3 \mathrm{~d}$ and then milk until $23 \mathrm{~d}$ of age at $20 \%$ of BW, which was gradually reduced (between $\mathrm{d} 24$ and 28 ) to $10 \%$ of BW for the remaining $16 \mathrm{~d}$ of the weaning period. Calves in both the conventional and STEP groups were weaned gradually by diluting milk with water between 45 and $49 \mathrm{~d}$ of age. 
Table 7. Average ruminal total VFA, acetate, propionate, butyrate and plasma BHBA concentrations in Holstein male calves fed milk through either a conventional $(n=20)$ or step-down (STEP, $n=20)$ procedure $^{1}$

\begin{tabular}{lccc}
\hline Parameter & Conventional & STEP & SEM \\
\hline Total VFA, $\mu$ mol/L & & & \\
At STEP $(\mathrm{d} 28)$ & $57.82^{\mathrm{a}}$ & $49.02^{\mathrm{b}}$ & 3.48 \\
At weaning $(\mathrm{d}$ 49) & $69.82^{\mathrm{b}}$ & $88.98^{\mathrm{a}}$ & 4.12 \\
At postweaning $(\mathrm{d}$ 63) & $103.25^{\mathrm{b}}$ & $124.01^{\mathrm{a}}$ & 6.23 \\
Acetate, $\mu$ mol/L & & & \\
At STEP & $28.45^{\mathrm{a}}$ & $25.25^{\mathrm{b}}$ & 1.36 \\
At weaning & $35.42^{\mathrm{b}}$ & $46.86^{\mathrm{a}}$ & 2.95 \\
At postweaning & $55.21^{\mathrm{b}}$ & $66.39^{\mathrm{a}}$ & 4.12 \\
Propionate, $\mu \mathrm{mol} / \mathrm{L}$ & & & \\
At STEP & $16.79^{\mathrm{a}}$ & $14.15^{\mathrm{b}}$ & 1.33 \\
At weaning & $19.04^{\mathrm{b}}$ & $25.01^{\mathrm{a}}$ & 1.54 \\
At postweaning & $28.21^{\mathrm{b}}$ & $33.61^{\mathrm{a}}$ & 2.33 \\
Butyrate, $\mu \mathrm{mol} / \mathrm{L}$ & & & \\
At STEP & $8.84^{\mathrm{a}}$ & $6.28^{\mathrm{b}}$ & 0.94 \\
At weaning & $10.23^{\mathrm{b}}$ & $12.21^{\mathrm{a}}$ & 0.84 \\
At postweaning & $12.67^{\mathrm{b}}$ & $14.36^{\mathrm{a}}$ & 1.01 \\
BHBA, mmol/L & & & \\
At step & 0.07 & 0.06 & 0.004 \\
At weaning & $0.09^{\mathrm{b}}$ & $0.13^{\mathrm{a}}$ & 0.005 \\
At postweaning & $0.11^{\mathrm{b}}$ & $0.16^{\mathrm{a}}$ & 0.007 \\
\hline
\end{tabular}

${ }^{\mathrm{a}, \mathrm{b}}$ Within traits, means with different superscript letters are different $(P<0.05)$

${ }^{1}$ In the conventional method, the calves were fed colostrum for 3 $\mathrm{d}$ and then milk at $10 \%$ of BW until $44 \mathrm{~d}$ of age. In the STEP method, the calves were given colostrum for $3 \mathrm{~d}$ and then milk until $23 \mathrm{~d}$ of age at $20 \%$ of BW, which was gradually reduced (between $\mathrm{d} 24$ and 28 ) to $10 \%$ of BW for the remaining $16 \mathrm{~d}$ of the weaning period. Calves in both the conventional and STEP groups were weaned gradually by diluting milk with water between 45 and $49 \mathrm{~d}$ of age.

in conventionally fed calves than in those fed through the STEP procedure (Figure 3 ). The treatment $\times$ time interaction at $63 \mathrm{~d}$ was significant for glucagon $(P<$ 0.04) and for insulin $(P<0.03)$.

Table 8. Forestomach measurements in Holstein male calves ${ }^{1}$ fed milk through either a conventional $(\mathrm{n}=6)$ or step-down (STEP, $\mathrm{n}=$ 6) procedure $^{2}$

\begin{tabular}{lccc}
\hline Parameter & Conventional & STEP & SEM \\
\hline Ruminal weight, kg & $1.37^{\mathrm{b}}$ & $1.89^{\mathrm{a}}$ & 0.13 \\
Reticulum weight, kg & $0.18^{\mathrm{b}}$ & $0.29^{\mathrm{a}}$ & 0.03 \\
Omasum weight, kg & $0.53^{\mathrm{b}}$ & $0.68^{\mathrm{a}}$ & 0.11 \\
Abomasum weight, kg & $0.57^{\mathrm{b}}$ & $0.71^{\mathrm{a}}$ & 0.10 \\
Ruminal wall thickness, cm & $1.15^{\mathrm{b}}$ & $1.47^{\mathrm{a}}$ & 0.05 \\
Papillae length, cm & $0.71^{\mathrm{b}}$ & $0.96^{\mathrm{a}}$ & 0.07 \\
Papillae width, cm & $0.48^{\mathrm{b}}$ & $0.62^{\mathrm{a}}$ & 0.01 \\
Papillae concentration, $\mathrm{n} / \mathrm{cm}^{2}$ & $71.0^{\mathrm{b}}$ & $86.0^{\mathrm{a}}$ & 3.00 \\
\hline
\end{tabular}

${ }^{a, b}$ Within traits, means with different superscript letters are different $(P<0.05)$.

${ }^{1}$ Calves were randomly selected and slaughtered at $63 \mathrm{~d}$ of age.

${ }^{2}$ In the conventional method, the calves were fed colostrum for 3 $\mathrm{d}$ and then milk at $10 \%$ of BW until $44 \mathrm{~d}$ of age. In the STEP method, the calves were given colostrum for $3 \mathrm{~d}$ and then milk until $23 \mathrm{~d}$ of age at $20 \%$ of BW, which was gradually reduced (between $\mathrm{d} 24$ and 28 ) to $10 \%$ of BW for the remaining $16 \mathrm{~d}$ of the weaning period. Calves in both the conventional and STEP groups were weaned gradually by diluting milk with water between 45 and $49 \mathrm{~d}$ of age.

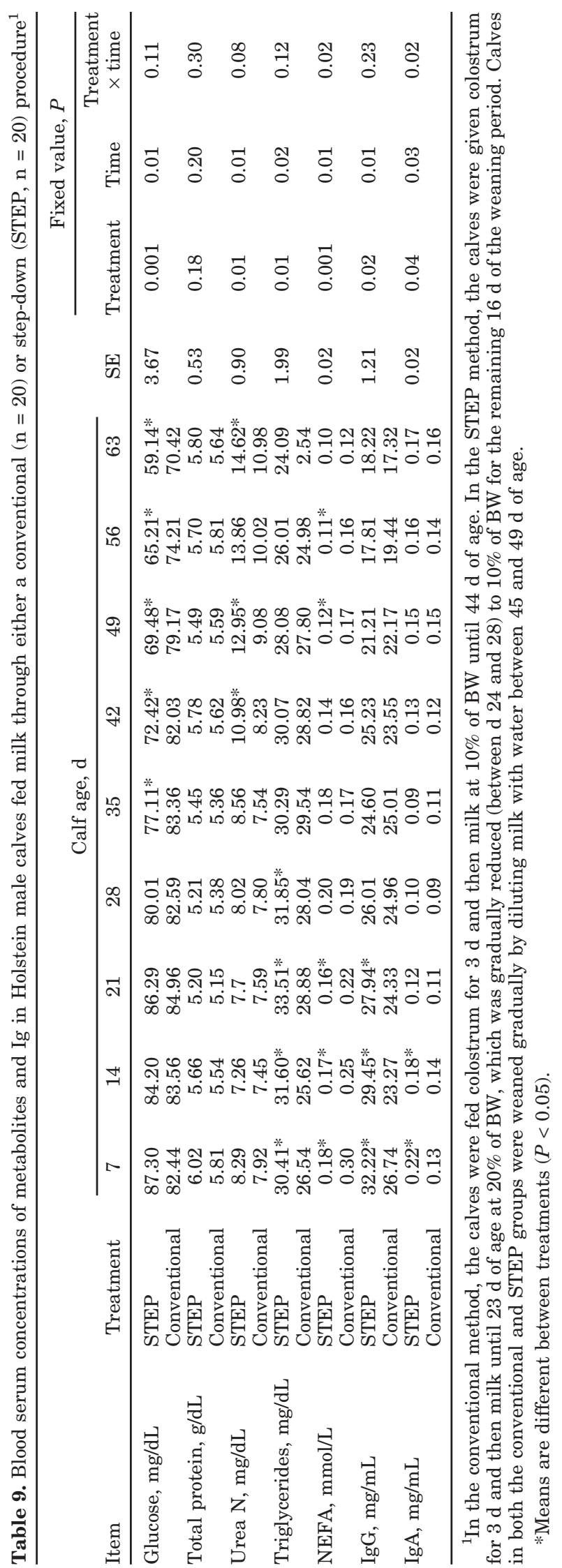

Journal of Dairy Science Vol. 90 No. 7, 2007 

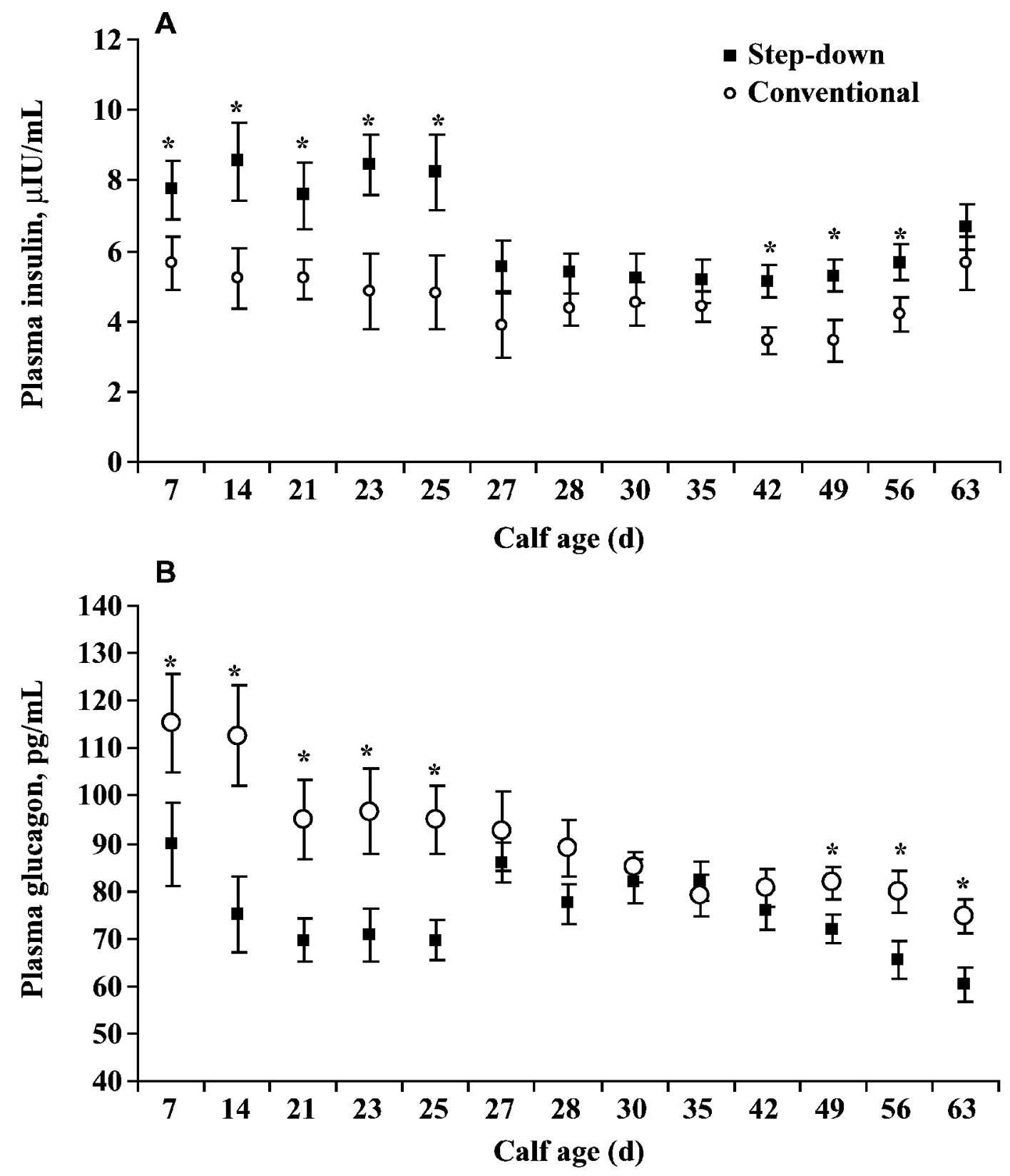

Figure 3. Mean $( \pm \mathrm{SE})$ concentration of plasma insulin (A) and glucagon (B) in Holstein male calves. Values are shown separately for Holstein male calves fed milk either conventionally $(n=20)$ or through a step-down (STEP; $n=20)$ procedure. In the conventional method, calves were fed colostrum for $3 \mathrm{~d}$ and then milk at the rate of $10 \%$ of their BW until d 44 of age. In the STEP method, calves were given colostrum for $3 \mathrm{~d}$ and then milk until $23 \mathrm{~d}$ of age at $20 \%$ of their BW, which was gradually reduced (between d 24 and 28 ) to $10 \%$ of their BW for the remaining $16 \mathrm{~d}$ of the weaning period. Calves in both the conventional and STEP groups were weaned gradually by diluting milk with water between d 45 and 49 of age. ${ }^{*}$ Means are different $(P<0.05)$ between groups. The time by treatment interaction was significant for glucagon $(P<0.04)$ and for insulin $(P<0.03)$.

\section{DISCUSSION}

Holstein calves fed through the STEP method safely consumed significantly higher amounts of milk than those fed conventionally. The occurrence of diarrhea, the rectal temperature respiratory score, and the gen- eral appearance score in calves were not affected by the milk-feeding method. Similar results were demonstrated in our previous experiment (Khan et al., 2007), in which female Holstein calves on the STEP feeding system consumed significantly higher amounts of milk than those fed through the conventional system. Calves 
can consume and digest greater amounts of milk than typically given under the conventional feeding system, particularly when provided as small, frequent meals, similar to those observed under natural conditions (Albright and Arave, 1997). Greater daily milk consumption in ad libitum milk-fed calves can increase their digestive capacity (de Passillé et al., 1992) and thus probably enable them to handle large quantities of milk. A high incidence of diarrhea is usually related to the sanitary, management, and housing conditions of the calves rather than their daily amount of milk intake (Hammon et al., 2002).

The higher serum IgG and IgA titers in STEP-fed calves during the pre-STEP period could be attributed to the greater supply of nutrients from higher milk consumption. Nutritional insufficiency can badly influence immune function and may increase the susceptibility of neonatal calves to infectious disease (Nonnecke et al., 2003). Nutrition is a critical determinant of immune responses, with the protein and energy supply influencing cell-mediated immunity, cytokine production, the complement system, phagocytic functions, and secretory IgA antibody concentrations (Woodward, 1998). In the neonatal calf, the plane of nutrition during the first month of life specifically affects the somatotropic axis (Smith et al., 2002). Smith et al. (2002) found that increased nutrient intake sufficient to optimize growth performance was associated with elevated plasma IGF-I, insulin, and glucose concentrations. Their data also demonstrated that in well-nourished calves, the somatotropic axis is functionally coordinated with and sensitive to nutrient intake and growth hormone. Because the somatotropic axis influences developmental and functional aspects of the immune system (Clark, 1997), the greater milk consumption of STEPfed calves probably benefited their immune system.

Increased milk consumption during the pre-STEP period probably depressed the solid feed consumption of calves fed milk through the STEP procedure. A significantly higher concentration of plasma insulin and a significantly lower concentration of plasma glucagon during the pre-STEP phase indicated a hypophagic condition in STEP-fed calves compared with those fed conventionally. Numerically higher blood glucose and triglyceride concentrations, and significantly lower blood NEFA concentrations during the pre-STEP period in STEP-fed calves also support the above notion. For the first few weeks of life, calves are more dependent on milk or milk replacer as their main dietary energy source and therefore mobilize NEFA before feeding (Stanley et al., 2002). A higher preprandial blood NEFA concentration in conventionally fed calves during the pre-STEP period may reflect the initiation of lipolysis at least a few hours preprandially to meet the diminishing energy supply. We suggest that the hypophagic condition caused by the chemical (higher blood glucose and insulin) and mechanical (continuous gut-filling because of curd formation) stimuli depressed starter and hay intake in STEP-fed calves during the pre-STEP phase. Forbes (1986) describes an inverse relationship between the amount of milk offered to calves and their dry feed consumption during the preweaning period. Previously, Jasper and Weary (2002) reported a depression in solid feed consumption when dairy calves were fed higher amounts of milk.

The rapid increase in starter and hay intake during and a few days after STEP-feeding of calves may be attributed to a hyperphagic response caused by the reduced supply of milk and nutrients. Blood glucose and plasma insulin concentrations were reduced, and plasma glucagon was increased in STEP-fed calves with the reduction in milk supply ( $\mathrm{d} 27,28,30$, and 35 ). Greater nutrient demands, because of the higher BW and increased size of digestive organs (Bøe and Havrevoll, 1993) resulting from increased milk consumption during the pre-STEP phase, probably further triggered the hyperphagicity in STEP-fed calves during the milk reduction period and in the following days. Khan et al. (2007) also reported a rapid surge in solid feed consumption when the milk supply to STEP-fed female calves was reduced. Similarly, Abdelsamei et al. (2005) indicated that a decrease in milk replacer consumption linearly increased the intake of hay by Holstein calves. The surge in solid feed consumption in both STEPfed and conventionally fed calves during weaning and postweaning also reflected the hyperphagic response. However, the significantly higher blood NEFA concentration at d 49 and 56 indicated mobilization of body fat because of somewhat higher nutritional transition stress in conventionally fed calves than in those fed through the STEP system. Higher blood BHBA and BUN concentrations, and lower blood glucose and NEFA concentrations at weaning and postweaning in STEP-fed calves could be attributed to the start of some ruminal fermentation earlier than in those fed conventionally. Although solid feed is eaten in small quantities by calves, they are not usually eating enough to support full growth at weaning. If solid feed can be encouraged during the milk-feeding period, then the check on growth (because of the nutritional transition) at weaning will be less severe (Forbes, 1986). Low blood glucose and NEFA concentrations and higher BUN and BHBA concentrations at weaning indicated an earlier nutritional or metabolic transition in STEP-fed calves than in those fed conventionally.

The increased feed intake observed in STEP-fed calves during the postweaning period may be due to the increase in solid feed consumption observed during 
the preweaning period, which resulted in a greater BW and improved rumen function (Baldwin et al., 2004). Greater concentrations of ruminal total VFA, acetate, propionate, and butyrate at weaning and postweaning and their lesser concentrations at STEP-feeding in calves fed through the STEP method, compared with those fed conventionally, mimic the pattern of solid feed intake. Greater consumption of both starter and hay by STEP-fed calves during the weaning and postweaning periods resulted in early initiation of ruminal fermentation compared with those fed conventionally.

The higher RTW, PL, PW, papillae concentration, and weight of the forestomach in STEP-fed calves may be attributed to their higher solid feed intake and earlier initiation of ruminal fermentation compared with conventionally fed calves. Following initiation of solid feed intake and subsequent establishment of ruminal fermentation by the calf, the rumen undergoes both physical and metabolic development (Baldwin et al., 2004). Physical development of the rumen can be further partitioned into 2 aspects: increases in rumen mass, and growth of the papillae. Early research indicated that physical stimulation of the rumen by feed could account for measurable increases in both rumen weight and musculature development. However, the presence of physical bulk alone does not promote papillary development (Hamada et al., 1976). Thus, for normal development of the ruminal epithelium to progress, viable ruminal fermentation must be established, suggesting that there is a requirement that short-chain fatty acids (especially propionate and butyrate) be present in the ruminal lumen to promote normal papillary development (Sander et al., 1959; Suárez et al., 2006). It may be suggested that the early initiation and greater consumption of starter and hay may have provided higher chemical and physical stimuli, respectively, and thereby resulted in higher RTW, PL, PW, papillae concentration, and weight of the forestomach in STEP-fed calves compared with those fed conventionally.

Lower blood glucose and higher BUN and BHBA concentrations at weaning and postweaning further signify the better ruminal function of STEP-fed calves compared with those fed conventionally. These metabolic changes clearly indicate a physiological fuel shift in the primary energy source from glucose to VFA in calves with a functional rumen. One of the most defining characteristics of a fully developed, functioning foregut in a fed, nonpregnant, nonlactating animal is ruminal production of ketones (Baldwin et al., 2004). Plasma BHBA is a measure of rumen epithelial metabolic activity and indicates conversion of rumen butyrate to BHBA as it passes through the rumen wall (Lane et al., 2000). Quigley et al. (1991) and Quigley (1996) have demonstrated that in young calves, the rumen epithelium has the capacity to absorb and metabolize VFA from an early age onward. Consequently, in rearing calves, increased rumen VFA concentrations are associated with high plasma BHBA concentrations. Higher BUN concentrations at weaning and postweaning could be ascribed to a higher ruminal ammonia concentration in STEP-fed calves than in those fed conventionally. Greater protein intake because of higher solid feed consumption and its ruminal degradation resulted in higher concentrations of ruminal ammonia and BUN in STEP-fed calves than in those fed conventionally. A higher concentration of BUN is also an index of renal dysfunction; however, in our previous study (Khan et al., 2007) the creatinine concentration in calves fed through the STEP and conventional methods was in the safe range and did not differ between treatments. The noticeably lesser blood glucose and higher BUN and BHBA concentrations in STEP-fed calves than in conventionally fed calves at weaning and postweaning may be attributed to greater solid feed consumption, better ruminal fermentation, and thus greater reliance on its end-products to derive energy needs.

The higher $\mathrm{BW}$ gain and greater $\mathrm{BL}, \mathrm{HG}, \mathrm{BB}, \mathrm{WH}$, and HH at STEP in STEP-fed calves could be ascribed to greater nutrient availability from considerably greater milk consumption. Significantly greater BW gain, BL, $\mathrm{HG}, \mathrm{BB}, \mathrm{WH}$, and $\mathrm{HH}$ during the post-STEP period in calves fed milk through the STEP method may be attributed to greater consumption of starter and hay. The quantity of milk consumed by STEP-fed calves during the post-STEP period was also greater than in those fed conventionally. Greater BW gain, $\mathrm{BL}, \mathrm{HG}, \mathrm{BB}, \mathrm{WH}$, and $\mathrm{HH}$ during the postweaning period could be attributed to higher feed consumption and greater absorption of nutrients from a metabolically functional and developed rumen in calves on STEP feeding compared with those on conventional feeding.

\section{CONCLUSIONS}

The lower solid feed consumption in STEP-fed calves during the pre-STEP period may be attributed to a hypophapgic condition caused by greater milk consumption. A hyperphagic response during the postSTEP period triggered a surge in the consumption of starter and hay in STEP-fed calves. Earlier initiation of solid feed intake in calves on the STEP method, compared with those on the conventional method, resulted in a more metabolically and physically developed rumen in the former. The greater BW gain and body measurements in calves on the STEP method than in those on the conventional method could be ascribed to higher nutrient availability from considerably greater milk 
consumption and higher nutrient absorption because of a metabolically developed rumen.

\section{ACKNOWLEDGMENT}

This study was conducted as part of a postdoctoral research project funded by the National Livestock Research Institute, Rural Development Administration, South Korea.

\section{REFERENCES}

Abdelsamei, A. H., D. G. Fox, L. O. Tedeschi, M. L. Thonney, D. J. Ketchen, and J. R. Stouffer. 2005. The effect of milk intake on forage intake and growth of nursing calves J. Anim. Sci. 83:940-947.

Albright, L. L., and C. W. Arave. 1997. The Behaviour of Cattle. CABI, Wallingford, UK.

AOAC (Association of Official Analytical Chemists). 1990. Official Methods of Analysis. 15th ed. AOAC, Arlington, VA.

Baldwin, R. L. VI, K. R. McLeod, J. L. Klotz, and R. N. Heitmann. 2004. Rumen development, intestinal growth and hepatic metabolism in the pre- and post-weaning ruminant. J. Dairy Sci. 87:E55-E65.

Bøe, K., and Ø. Havrevoll. 1993. Cold housing and computer-controlled milk feeding for dairy calves: Behavior and performance. Anim. Prod. 57:183-191.

Broderick, G. A., and J. H. Kang. 1980. Automated simultaneous determination of ammonia and total amino acids in ruminal fluid and in vitro media. J. Dairy Sci. 63:64-75.

Clark, R. 1997. The somatogenic hormones and insulin-like growth factor-1: Stimulator of lymphopoiesis and immune function. Endocr. Rev. 18:157-179.

de Passillé, A. M. B., J. H. M. Metz, and P. R. Wiepkema. 1992. Does drinking milk stimulate sucking in young calves? Appl. Anim. Behav. Sci. 34:23-36.

Flatt, W. P., R. Warner, and J. K. Loosli. 1958. The influence of purified materials on the development of the ruminant stomach. J. Dairy Sci. 41:1593-1600.

Forbes, J. M. 1986. The Voluntary Intake in Farm Animals. 1st ed. Butterworth and Co. Ltd., London, UK.

Hamada, T., S. Maeda, and K. Kameoka. 1976. Factors influencing growth of rumen, liver, and other organs in kids weaned from milk replacers to solid foods. J. Dairy Sci. 59:1110-1118.

Hammon, H., and J. W. Blum. 1998. Metabolic and endocrine traits of neonatal calves are influenced by feeding colostrum for different durations or only milk replacer. J. Nutr. 128:624-632.

Hammon, H. M., G. Schiessler, A. Nussbaum, and J. W. Blum. 2002. Feed intake patterns, growth performance, and metabolic and endocrine traits in calves fed unlimited amounts of colostrum and milk by automate, starting in the neonatal period. J. Dairy Sci. 85:3352-3362.

Harrison, H. N., R. G. Warner, E. G. Sander, and J. K. Loosli. 1960. Changes in the tissue and volume of the stomachs of calves following the removal of dry feed or consumption of inert bulk. J. Dairy Sci. 43:1301-1312.
Heinrichs, A. J., C. M. Jones, L. R. VanRoekel, and M. A. Fowler. 2003. CalfTrack: A system of dairy calf workforce management, training, and evaluation and health evaluation. J. Dairy Sci. 86(Suppl. 1):115. (Abstr.)

Huzzey, J. M., M. A. G. von Keyserlingk, and D. M. Weary. 2005. Changes in feeding, drinking, and standing behavior of dairy cows during the transition period. J. Dairy Sci. 88:2454-2461.

Jasper, J., and D. M. Weary. 2002. Effects of ad libitum milk intake on dairy calves. J. Dairy Sci. 85:3054-3058.

Jensen, M. B. 2006. Computer-controlled milk feeding of grouphoused calves: The effect of milk allowance and weaning type. J. Dairy Sci. 89:201-206.

Khan, M. A., H. J. Lee, W. S. Lee, H. S. Kim, S. B. Kim, K. S. Ki, J. K. Ha, H. G. Lee, and Y. J. Choi. 2007. Pre- and post-weaning performance of Holstein female calves fed milk through stepdown and conventional methods. J. Dairy Sci. 90:876-885.

Lane, M. A., R. L. Baldwin, and B. W. Jesse. 2000. Sheep rumen metabolic development in response to age and dietary treatments. J. Anim. Sci. 78:1990-1996.

Lesmeister, K. E., P. R. Tozer, and A. J. Heinrichs. 2004. Development and analysis of a rumen tissue sampling procedure. J. Dairy Sci. 87:1336-1344.

Nonnecke, B. J., M. R. Foote, J. M. Smith, B. A. Pesch, and M. E. Van Amburgh. 2003. Composition and functional capacity of blood mononuclear leukocyte populations from neonatal calves on standard and intensified milk replacer diets. J. Dairy Sci. 86:35923604 .

NRC (National Research Council). 2001. Nutrient Requirements of Dairy Cattle. 7th rev. ed. Natl. Acad. Press, Washington, DC.

Quigley, J. D. 1996. Influence of weaning method on growth intake and selected blood metabolites in Jersey calves. J. Dairy Sci. 79:2255-2260.

Quigley, J. D., L. A. Caldwell, G. D. Sinks, and R. N. Heitmann. 1991. Changes in blood glucose, nonesterified fatty acids, and ketones in response to weaning and feed intake in young calves. J. Dairy Sci. 74:250-257.

Quigley, J. D., T. A. Wolfe, and T. H. Elsasser. 2006. Effects of additional milk replacer feeding on calf health, growth, and selected blood metabolites in calves. J. Dairy Sci. 89:207-216.

Sander, E. G., H. N. Warner, H. N. Harrison, and J. K. Loosli. 1959. The stimulatory effect of sodium butyrate and sodium propionate on the development of rumen mucosa in the young calf. J. Dairy Sci. 42:1600-1605.

SAS Institute. 1994. SAS User's Guide: Statistics. Version 6.11 Edition. SAS Inst., Inc., Cary, NC.

Smith, J. M., M. E. Van Amburgh, M. C. Diaz, M. C. Lucy, and D. E. Bauman. 2002. Effect of nutrient intake on the development of the somatotropic axis and its responsiveness to GH in Holstein bull calves. J. Anim. Sci. 80:1528-1537.

Stanley, C. C., C. C. Williams, B. F. Jenny, J. M. Fernandez, H. G. Bateman, II, W. A. Nipper, J. C. Lovejoy, D. T. Gnatt, and G. E. Goodlier. 2002. Effects of feeding milk replacer once versus twice daily on glucose metabolism in Holstein and Jersey calves. J. Dairy Sci. 85:2335-2343.

Suárez, B. J., C. G. Van Reenen, W. J. J. Gerrits, N. Stockhofe, A. M. van Vuuren, and J. Dijkstra. 2006. Effects of supplementing concentrates differing in carbohydrate composition in veal calf diets: II. Rumen development. J. Dairy Sci. 89:4376-4386.

Woodward, B. 1998. Protein, calories, and immune defenses. Nutr. Rev. 56:S84-S92. 